\title{
Economics Students Performance: Does Language Matter?
}

\author{
Norasibah Abdul Jalil*, Hamidah Yusof, Norimah Rambeli, \\ Gan Pei Tha, Awadh Ahmed Mohammed Gamal
}

Faculty of Management and Economics, Sultan Idris Education University, Malaysia

Copyright $\bigcirc 2019$ by authors, all rights reserved. Authors agree that this article remains permanently open access under the terms of the Creative Commons Attribution License 4.0 International License

\begin{abstract}
The purpose of this study is to identify language influence on students' performance. This study involves 55 undergraduate student who are taking the Economic Principles course at the Sultan Idris Education University. The specific objectives of the study are; to identify the choice of language for the examination, to determine students' exam performance in both languages, and lastly to measure mean score difference by language and by gender. The data are analyzed by using descriptive statistics, paired-sample-test, and one way ANOVA. Comparisons between the mean scores show students perform better in the exam conducted in Malay language compared to exams in English. The result of the paired-sample-test provides indication that there is a significant difference between the two mean scores. The one-way ANOVA test has recorded significant results in the exam conducted in English only. The findings provide two main implications. Firstly, there is a significant difference in students' performance when the exam is conducted in Malay and in English languages. It is highly recommended the exams are prepared in dual languages (English and Malay) in order to maximize the opportunity of the good and the weak students in English to achieve their highest score in the examination. Secondly, the results also reflect that the level of English language proficiency of the students at this institution is not at competitive level, or is weaker than their level of understanding in Malay language. In relating to this, the institution may want to reconsider the structure of the English program provided for the weak. This is a correction program so that in the long run the English language program and courses at the university succeeded in producing quality students in English proficiency; equivalent to their skills in Malay language domination.
\end{abstract}

Keywords English, Malay Language, Economics, Descriptive Tests, Inference

\section{Introduction}

Education in Malaysia has undergone several phases of change in line with the country's economic progress. The development of the education system in Malaysia after independence began in 1963 until 1975. The first level, from 1963 to 1965, emphasized the implementation of the Education Act 1961. The second stage started from 1966 to 1970 under the First Malaysia Plan. At this stage, the system is designed to solve the economic and social problems that arise at the time.

Subsequently, the third level, from 1971 to 1975 , was a modification of the education and training system to meet the needs of economic development and to produce more skilled manpower to launch the New Economic Policy. Entering 2010, education in Malaysia also goes hand in hand with current needs as the community also changes due to the modernization and globalization flows.

\section{Problem Statement}

In line with changes in time, the Malaysian education system implements policies related to intermediary language. The policy of Teaching and Learning Science in English (PPSMI) was implemented in 2003 under the administration of Tun Dr. Mahathir Mohammad. The purpose of this policy is to strengthen English proficiency among Malaysian students. However, after seven years of implementation, this policy was abolished in 2012 due to the rise of opposition from various parties, especially the Malays. Among the reasons are; 1) it contradicts the Act 152 of the Malaysian Constitution, 2) the performance of the Malay and rural areas students in Science and Mathematics subjects dropped, 3) lacking trained teachers and 4) rejection from the Malay language scholars, academicians, political members and non-governmental organizations (NGOs).

Today there is a re-call for English language usage in teaching and learning. The question which arises is; does 
language have any significant impact on students' performance? As the sequence of this question, the current study intends to investigate this issue further. Since this study is a preliminary study of the impact of language on the performance of the economics students, only 55 economics students participated in the research activity. The scope of the study focuses on the choice of language exams among the economic students and their performance in answering exams conducted in Malay and English languages. In particular, this study is conducted to achieve the following objectives; i) to identify students' choice of language for their economic examination, ii) to determine students' performance through scores obtained in exams conducted in Malay and English languages, and iii) to analyze the mean difference of the examination scores conducted in Malay language and English by gender.

\section{Literatures Review}

The national education system has undergone a structural change over time, especially in terms of language usage in teaching and learning. There are a huge number of literatures which put focus on this theme. However, only selected few are highlighted in the discussion. Hwah and Lan (2009) examined the effect of different language usage on Science students' achievement. The findings show that the difference in student scores in different languages is not significant. However, there is an indication that, students' achievement in the Malay language test is better than the one conducted in the English version.

Fong Peng and Zahari Ishak (2008); focused on the students' perception of the usage of Malay and English languages at public and private universities in the national education system. The findings show that students presumed Malay language is most suitable to be used as the medium of instruction in specific subjects namely Islamic subjects (mean 4.05), while English is the most suitable language for Medical subjects (mean 4.41). Students consider Malay language is least suitable for usage in Medical subjects (mean 2.19). The t-test also showed that there is a significant relationship (at the level of $\mathrm{p}<0.001$ ) between the public and the private university students on the usage of Malay and English languages in Science subjects in the education system.

Adibah Abdul Latif and Azizah Binti Abu Hanifah (2010), had conducted a study on the mastery and the usage of English among the PKPG (Special Program for Teacher Graduation) students at the Malaysian Technology University. The overall results show that the mastery and usage level of English among the respondents is relatively moderate; there is an indication that the mastery and usage factors are significantly related.

Maharam Mamat (2016) also conducted studies related to the influence of language and the specific focus was given on English proficiency among the first-year students at UKM. The results show that the English proficiency level of Year one students is at a moderate level with average MUET score of band 2. Based on observation, the respondents appeared to be among those who worked diligently to improve their English skills but they still lacked the ability to communicate and to write in English properly.

Shanmugam and Ong (2013) presented a study on the usage of language and its influence on the achievement of the less-skilled students (LSS). This study is to investigate the effects of bilingual tests (English and Malay) in Mathematics. A total of 2,021 students from 34 schools from Penang and Perak participated. The findings show the score difference between the tests is by one unit; this may be due to an equalization error. The researcher concluded, bilingual testing is not easier for the LSS students. This study however figures out that, adaptation of the Malay language in the teaching and learning process provide help to the students to understand the question better.

Hamdan Azmi Abd. Aziz and Noor Rohana Mansor (2013) conducted a study that aimed at exploring the perception of academicians on Malay language's ability in functioning as the main medium of instruction in the Science and Technology field at higher education institutions. The study includes analyses that tested Malay language used as the medium of instruction in the teaching and learning process of the field; in the situation where English has been given a priority to play that function at the tertiary education level. The findings showed the usage of Malay language is relatively high in lecture delivery (62.7 percent) and lecture-discussion (54.7 percent) activities. A higher percentage of these two activities helps to accelerate the understanding of the students. In the meantime, the English proficiency factor among students and academic staffs also contributes a relatively lower degree than Bahasa Malaysia, to the usage of the language as the medium of instruction in both teaching and learning activities. In conclusion, this study has shown that confidence in Bahasa Malaysia remains high although Malay language is no longer the main language in IPT.

A study conducted by Nizamuddin Alias and Farid Sufian Shuhaib (2015) put focus on the position, status, and role of Malay language in Malaysia. Based on the findings they conclude; language is the most basic instrument used in human communication. Countries with various ethnic and linguistic groups are unable to communicate well without using the appropriate language. Therefore, every member of society should use the same language so that communication is more understandable to each other. This study emphasizes the role of language especially Malay language in communicating better.

\section{Methodology}

In general, this research is an exploratory study which 
provides preliminary findings of the focused issue. A total of 55 respondents who took Economic Principles course at the Sultan Idris Education University (UPSI) in Tanjung Malim; Perak, participated in this study. The instrument used for data collection is questionnaire set of two versions, English and Malay languages. The exam was conducted in both languages, in separate sessions and sequentially. The data obtained are processed by using SPSS version 23, are analyzed by using descriptive and inference (paired sample and Anova tests) methods.

\section{Findings}

This section comprises two parts. The first part discusses the demographic information of the respondents involved in this study and the second part elaborates on the findings related to the objectives of the study.

\subsection{Demographic Analysis}

The respondents' details are shown in Table 1.
Table 1. Respondents' Profile

\begin{tabular}{|c|c|c|c|}
\hline \multicolumn{2}{|c|}{ Item } & \multirow{2}{*}{$\begin{array}{c}\text { Frequency } \\
5 \\
\end{array}$} & \multirow{2}{*}{$\begin{array}{c}\text { Percent } \\
9.1 \\
\end{array}$} \\
\hline Gender & Male & & \\
\hline & Female & 50 & 90.9 \\
\hline & Total & 55 & 100 \\
\hline \multirow[t]{3}{*}{ Race } & Malay & 54 & 98.2 \\
\hline & Others & 1 & 1.8 \\
\hline & Total & 55 & 100 \\
\hline
\end{tabular}

Table 1 shows the demographic profile of the respondents specifically by the following items; gender and race. This study involves 55 students, five $(9.1 \%)$ males, and $50(90.9 \%)$ female students. The race distribution showed; all (98.2\%) respondents are among Malay students except one (1.8\%) who is from non-Malay background.

\subsection{Analysis of Language Preference for Examination}

This section analyses the students' choice of language for examination implementation and the results obtained are shown in Tables $2 \mathrm{a}$ and $2 \mathrm{~b}$.

Table 2a. Level of Preference Whether Exam to be Conducted In Malay Compared to English

\begin{tabular}{|c|c|c|c|c|}
\hline \multicolumn{2}{|c|}{ Level of preference exam to be conducted in Malay or English } & \multirow{2}{*}{ frequency } & \multirow{2}{*}{ Percent } & \multirow{2}{*}{ Cum. Percent } \\
\hline \multicolumn{2}{|c|}{ Malay (\%) vs. English (\%) } & & & \\
\hline 30 & 70 & 3 & 5.5 & 5.5 \\
\hline 40 & 60 & 2 & 3.6 & 9.1 \\
\hline 50 & 50 & 9 & 16.4 & 25.5 \\
\hline 60 & 40 & 4 & 7.3 & 32.7 \\
\hline 65 & 35 & 1 & 1.8 & 34.5 \\
\hline 70 & 30 & 10 & 18.2 & 52.7 \\
\hline 80 & 20 & 11 & 20.0 & 72.7 \\
\hline 85 & 15 & 2 & 3.6 & 76.4 \\
\hline 90 & 10 & 6 & 10.9 & 87.3 \\
\hline 100 & 0 & 7 & 12.7 & 100.0 \\
\hline \multicolumn{2}{|c|}{ Total } & 55 & 100.0 & \\
\hline
\end{tabular}


Based on the displayed results, there are mixed types of choices and different degrees of students' preference of whether the exams should be conducted in Malay or English language. In specific, nine persons (16.4\%) choose to be neutral, i.e. expressing no difference in degree of preference between the two languages. The percent of students favoring the exam to be conducted in English compared to Malay is about $9.1 \%$, while the percent of students favoring exam to be held in Malay than English is estimated around $74.55 \%$. For those who prefer Malay than English; the majority (38.2\%) agree at a high level $(70-80 \%)$, while five $(9.1 \%)$ students agree at a medium-high (60-65\%) level, and 15 persons relatively agree at a very high level $(\geq 85 \%)$.

The result of the analysis of mean score values is displayed in Table $2 b$. Based on the findings, the Malay language preference mean score is 71.18, which is relatively much higher than English preference mean score of 28.82 .

Table 2b. Mean Score of Examination Language Preference

\begin{tabular}{|c|c|c|}
\hline Language Preference & Mean & Std. Dev. \\
\hline Malay & 71.78 & 19.625 \\
\hline English & 28.82 & 19.625 \\
\hline
\end{tabular}

Based on the results obtained, the mean score for the exam conducted in Malay language is higher (71.78) than the mean score for English (28.82). This may be due to the background of the students who mainly come from the Malay race, and moreover, according to Ahmad Rizal Mohd Yusof, Mohd Firdaus Hamdan, Shamsul Amri Baharuddin, \& Mohd Syariefudin Abdullah (2017), Malay language has been the main language of communication to the Malaysian society. Here we may imply, students are more comfortable the exam to be conducted in Malay language because it is not only due to the fact that Malay language is their mother tongue language, but it is also their national language. Their skill to communicate in Malay provides them an advantage when dealing with exams which are conducted in Malay language. This association is in line with Zulkifley Hamid, Naidatul Zamrizam Abu, \& Asyraf Zulkifley (2015) who claimed effective oral communication requires speakers to comply with language systems that include linguistic, social systems and pragmatic aspects. In simple words, effective verbal communication between students and faculty in a particular language, no doubt is also affecting students' preference in their academic activity, specifically in their choice of language for lecture delivery and in examination.

\subsection{Performance Analysis}

The discussion for this section is divided into three parts. The first part analyzes the exam scores in both languages, the second part is the test of means difference between the two exam scores (the paired sample test); and the last is the test of means difference of the exam scores (between the two languages) by gender.

\subsubsection{Exam Score Analysis}

The overall results are shown in Table 3.

Table 3. Examination Score In Both Languages

\begin{tabular}{|c|c|c|c|c|c|}
\hline & & \multicolumn{3}{|c|}{ Exam Scores } & \\
\hline Languages & N & Minimum & Maximum & Mean & $\begin{array}{c}\text { Std. } \\
\text { Deviation }\end{array}$ \\
\hline Malay & 55 & 10 & 87 & $\mathbf{6 4 . 2 9}$ & 14.410 \\
\hline English & 55 & 20 & 73 & $\mathbf{4 7 . 9 1}$ & 11.439 \\
\hline Total & 55 & & & & \\
\hline
\end{tabular}

Table 3 shows the students' score in the exams conducted in Malay and English languages. The documented mean score for the examination conducted in Malay language is 64.29 which is higher than the English exam mean score of 47.95 . This finding provides indication that students are getting a higher score when they answer the exams in Malay language compare to English.

\subsubsection{Test of Means Difference of the Exam Scores}

After obtaining the mean score values for the examination conducted in both languages, the next question arises here; are the two scores statistically different? The paired sample test is conducted, and the overall results are shown in Table 4.

Table 4. Test of Means Difference of the Exam Scores

\begin{tabular}{|c|c|c|c|c|c|c|c|c|}
\hline \multicolumn{9}{|c|}{ Paired Samples Test } \\
\hline \multirow{3}{*}{$\begin{array}{l}\text { Language } \\
\text { Preference }\end{array}$} & \multicolumn{5}{|c|}{ Paired Differences } & \multirow{3}{*}{$\mathrm{t}$} & \multirow{3}{*}{$\mathrm{df}$} & \multirow{3}{*}{$\begin{array}{c}\text { Sig. } \\
\text { (2-tailed) }\end{array}$} \\
\hline & \multirow{2}{*}{ Mean } & \multirow{2}{*}{ Std. Deviation } & \multirow{2}{*}{ Std. Error Mean } & \multicolumn{2}{|c|}{$95 \%$ Confidence Interval of the Difference } & & & \\
\hline & & & & Lower & Upper & & & \\
\hline $\begin{array}{l}\text { Malay } \\
\text { English }\end{array}$ & 42.364 & 39.251 & 5.293 & 31.753 & 52.975 & 8.004 & 54 & .000 \\
\hline
\end{tabular}


Based on the results obtained in Table 4, the value of $\mathrm{P}$ is significant at $1 \%$ significance level. Here we may conclude, there is a significant difference in the mean values between the scores obtained from the exam conducted in Malay and English languages.

\subsubsection{Test of Means Difference of the Exam Scores (between the Two Languages) by Gender}

Issues of gender differences in various aspects of life have been studied by many researchers around the world. In the context of education, the gender gap associated with academic performance is still one of the interesting issues to be studied (Zalizan Mohd Jelas, Saemah Rahman, Roselan Baki, \& Jamil Ahmad, 2005). In relating to this, a one-way Anova test is conducted to figure out whether there is a means difference of the scores obtained in the Malay language test, followed by the scores obtained in the English test. Comparison for each test is made by gender. The overall results of this test are shown in Table 5.

Table 5. Test of Mean Difference of Scores for examination conducted in Malay Language, by gender

\begin{tabular}{|c|c|c|c|c|c|}
\hline & $\begin{array}{c}\text { Sum of } \\
\text { Squares }\end{array}$ & df & $\begin{array}{c}\text { Mean } \\
\text { Square }\end{array}$ & F & Sig. $(\alpha=5 \%)$ \\
\hline Between Groups & 205.265 & 1 & 205.265 & .988 & .325 \\
\hline Within Groups & 11008.080 & 53 & 207.700 & & \\
\hline Total & $\mathbf{1 1 2 1 3 . 3 4 5}$ & $\mathbf{5 4}$ & & & \\
\hline
\end{tabular}

Based on the results obtained, the P-value is observed to be more than 0.05 . The mean difference of the exam score (conducted in Malay language) by gender is insignificant. Here we may imply, there is no significant difference in the score obtained by the female students and the male students in the examination conducted in Malay language. This also shows that students' ability; regardless of gender, to answer the examination questions conducted in Malay language is relatively equal.

Table 6. Test of Mean Difference for Examination Scores conducted in English, by gender

\begin{tabular}{|c|c|c|c|c|c|}
\hline & $\begin{array}{c}\text { Sum of } \\
\text { Squares }\end{array}$ & df & $\begin{array}{c}\text { Mean } \\
\text { Square }\end{array}$ & F & Sig. $(\alpha=5 \%)$ \\
\hline $\begin{array}{c}\text { Between } \\
\text { Groups }\end{array}$ & 1606.545 & 1 & 1606.545 & 15.595 & .000 \\
\hline $\begin{array}{c}\text { Within } \\
\text { Groups }\end{array}$ & 5460.000 & 53 & 103.019 & & \\
\hline Total & 7066.545 & 54 & & & \\
\hline
\end{tabular}

In the following test, the mean difference of the exam score conducted in English; by gender, is significant as the $\mathrm{P}$-value is less than $0.05, \mathrm{P}<0.05$. This means that the Null Hypothesis (H0) is rejected. Here we may infer, there is significant difference in the examination scores obtained by the male and the female students in the exam conducted in English.

\section{Conclusions}

This study is carried out to identify students' exam language preference; either Malay or English, and to determine students' performance in answering the exam questions in both languages. In language preference analysis, students tend to favor Malay language than English. The findings for the performance analysis, higher scores are recorded in the examination conducted in the Malay language compared to English. The means difference in the score analysis found a significant difference in the min score values between the exam conducted in Malay language and in English. For the one-way ANOVA test; the results provide indication of significant result in the test conducted in English only. The findings provide some implications for related parties. The main two implications are; Firstly, the results show, there is a significant difference in students' performance when the exam is conducted in Malay language and in English. This provides an indication that the exam questions should be prepared in bilingual format; not a single-language examination (English). This activity may not help the institution to save papers, or save lecturers' time in exam question preparation, but it maximizes opportunity to both types of students; the good and the weak in English, to achieve their highest score in the examination. Secondly, the results also reflect that the level of English language proficiency of the students at this institution is not at competitive level, or is weaker than their level of understanding in Malay language. In relating to this, the institution may want to reconsider the structure of the English program provided for the weak. This is a correction program so that in the long run the English language program and courses at the university succeeded in producing quality students in English proficiency; equivalent to their skills in Malay language domination.

\section{Acknowledgements}

We would like to thank UPSI and the Ministry of Education for awarding us the Niche Research Grant Scheme (NRGS) under code number: 2014-0001-107-82-4.

\section{REFERENCES}

[1] Adibah Abdul Latif and Azizah Binti Abu Hanifah (2010). [Mastery and Use of English among Students PKPG Students Living Skills at Universiti Teknologi Malaysia]. 1-13. (Unpublished)(In Malay) 
[2] Fong Peng, C. \&, \& Zahari Ishak. (2008). [Level of English and English Language Use among Students in IPTA and IPTS in the National Education System]. Jurnal Pendidikan Bahasa Malaysia, 19, 16-36.(In Malay)

[3] Hamdan Azmi Abd. Aziz \& Noor Rohana Mansor. (2013). [Perception of Academic Energy at Higher Education Institutions Against Indonesian Language Abilities Functioning as the Main Language of Knowledge]. Jurnal Pendidikan Bahasa Malaysia, 3 (2), 41-48. (In Malay)

[4] Hwah, L. P. \& Lan, O.S. (2009) Perbandingan Pencapaian Murid Dalam Ujian Sains Berdasarkan Versi Bahasa Inggeris Dan Bahasa Melayu (Comparing Students' Achievement For Science Test In English And In Malay Language). The Asia Pacific Journal of Educators and Education (formerly known as Journal of Educators and Education), 24 (1). pp. 1-22. ISSN 2289-9057

[5] Shanmugam, K. S. \& Ong, S. L. (2013). Using Bilingual Test to Assess Malaysian Limited English Proficient Students' Mathematics Achievement. Jurnal Pendidikan Malaysia, 38 (2), 11-22.

[6] Khalip Musa, \& Seng, N. N. (2015). Teacher Leadership Relationship with Student Academic Achievement in Sibu, Sarawak. Management Research Journal, 1 (2), 1-11.

[7] Maharam Mamat. (2016). [Mastery of English in Year One Students in UKM]. Issues in Language Studies, 5 (2), 28-42. (In Malay)

[8] Nizamuddin Alias and Farid Sufian Shuhaib (2015). Position, Status and Role of Malay Language in Malaysia, 4, 125-134. 